\section{P-218 ORANGELINE}

Jane Frame. Saint Francis Hospice, Romford, UK

\subsection{6/bmjspcare-2016-001245.239}

Background We will be launching a new non-clinical telephone helpline formally in September 2016. The Big Lottery (BIG) agreed to fund this exciting new project for three years and this innovative and much needed service will be branded as 'Orangeline'.

Aim We are mindful that there are some people with life limiting illnesses, and their friends and carers, who are living in an isolated world with little communication outside of their immediate circle, some are totally alone. Orangeline will give people a link into Saint Francis Hospice for support and friendship and the opportunity to be signposted to our services such as occupational therapy, complementary therapy and our bereavement services.

Method Our Orangeline service will be centrally based within the day therapy unit and will be managed by two members of staff and a team of volunteers within our Quality and Care Directorate. Orangeline will operate later into the evening and weekends, these are times when people living or not coping well alone are at their most vulnerable, how lovely will it be to have a friendly caring voice on the end of the telephone, or even better to come into see us for lunch on a Sunday and meet new friends. We have so many great ideas and would welcome the opportunity of sharing the success of this new project at the Hospice UK conference in November.

Results Our aim for this service will be the catalyst for reaching out to people already known to us and many more out in the community who aren't. We believe it will be the start of something BIG. As the project rolls out we will concentrate resources on evaluating outcomes, and assessing the benefits to people's health, wellbeing and recovery.

\section{P-219 DOES ENGAGING WITH SOCIAL MEDIA BENEFITS HOSPICES? CASE STUDY ANALYSIS OF SOCIAL MEDIA PRESENCE OF FOUR UK HOSPICES}

${ }^{1}$ Munikumar Ramasamy Venkatasalu, ${ }^{2}$ Sivakumar Subramaniam. ${ }^{1}$ Universiti Brunei Darussalam, Gadong, Brunei Darussalam; ${ }^{2}$ Ellenor Lions Hospice, Northfleet, Kent, UK

\subsection{6/bmjspcare-2016-001245.240}

Background Emerging evidences suggest that use of social media helps to share information and resources and reach intended and 'beyond' audiences with quick and fast manner. Currently, hospices around the UK and the world actively engage with social media with different purposes. Yet, little is reported around the role of social media and its benefits for hospices.

Aim To investigate the use, engagement and the reach-out of social media among four hospices in the UK.

Methods A qualitative case study approach was adopted; studying purposeful sampling of four social media engaged hospices within UK. Data collection used multiple methods to collect publically available data that include feeds, comments, shares, tweets, status updates from two online social networking sites namely Facebook and Twitter of selected hospices. Using Nivio10 ${ }^{\circledR}$, a thematic analysis was undertaken.

Results Analysis of data found that all the hospices were actively engaged mainly in four different activities; fundraising, sharing best clinical practices, promoting educational activities, and adverting jobs. Hospices also involved in community outreach activities by celebrating local events and cultural and religious celebrations.

Conclusion Findings indicate that engagement with social media enable hospices to remain in 'core businesses' of 'running with local support'. Yet, hospices could be more explicit in sharing about how well it benefits for patients and carers that could enable access to hospice services across the diverse population by sharing stories of hospice patients and relatives' experiences.

\section{P-220 DEATH AND GRIEF ONLINE: THE OPPORTUNITIES AND CHALLENGES OF INCORPORATING DIGITAL LEGACIES INTO PALLIATIVE CARE IN HOSPICE SETTINGS}

${ }^{1}$ Jacklyn Pollock, ${ }^{2}$ Thomas Calvard. 'St Columba's Hospice, Edinburgh, UK; ${ }^{2}$ University of Edinburgh, UK

\subsection{6/bmjspcare-2016-001245.241}

One implication of social media is that when we die, we live on to an extent through our online presence and digital footprint or legacy. By 2098, for instance, dead Facebook users will outnumber living ones (Newsweek, 2016), effectively making the website into the largest graveyard in the world, albeit in digital form. The terminally ill, as well as their families and friends, can use these internet pages in various ways, as a legacy, tribute and memorial for addressing loss and bereavement.

In recent years, various enterprises, services, and associations have sprung up (e.g. Dead Social, the Digital Beyond, Final Road Map, and the Digital Legacy Association) with powerful implications for linking interactive digital tools like social media and blogging to the work of palliative healthcare professionals. Longer lifespans combined with widespread technological trends are inevitably reshaping experiences and perceptions of death and grief - with compelling questions for how palliative care can use such trends to improve its practices. Depending on how they are used, digital assets and legacies may help support people's coping and grieving processes, or they may have more negative effects, inhibiting acceptance and prolonging more dysfunctional responses to grief and loss.

Through research into the development of the Digital Legacy movement, and an ongoing programme of semi-structured interviews with hospice staff, technological innovators, patients and bereaved parties, this paper is aimed at critically assessing how effective palliative care might be delivered through various digital legacy services. Implications and conclusions are drawn for finding out and addressing the needs of patients and grieving relatives through online media, integrating digital legacies with existing palliative frameworks to improve care, and the ethical challenges of using new technologies to engage the highly sensitive, taboo subjects of dying and death.

\section{P-221 WORKING WITH HOSPICES TO ENSURE PATIENTS' DIGITAL LEGACY WISHES ARE ADHERED TO}

1,2 James Norris, ${ }^{3,4}$ Mark Taubert. 'Digital Legacy Association, London, UK; ${ }^{2}$ DeadSocial; ${ }^{3}$ NHS UK; ${ }^{4}$ Velindre Centre, Cardiff

10.1136/bmjspcare-2016-001245.242

The Digital Legacy Association (DLA) was launched at last year's Hospice UK conference. Their work is focused on raising awareness and improving processes in areas relating to death and the internet. 
Over the last 12 months the DLA have published a free framework, developed training workshops, launched a free hospice inpatient resource, run 'pop-up' events, organised a Digital Legacy conference, carried out different forms of research and campaigned highlighting that end of life and bereavement in relation to the internet and electronic devices is an area requiring thought, governance and change.

The DLA spend a lot of time working with hospices, CCGs, charities and trusts. The outcome is improved knowledge and skillsets applied at an organisational and/or at an individual level. The diffusion of the DLAs information occurs by supporting professionals through a variety of different channels. In turn this helps professionals to better support patients and their families.

The DLA's work often revolves around conversations and campaigning. Their recent work for Velindre NHS Trust, Aneurin Bevan UHB \& Byw Nawr included building a TalkCPR awareness website. The goal of the TalkCPR campaign is to help increase dialogue around CPR and DNACPR within Wales. The TalkCPR campaign was recently nominated for a NHS Wales award.

This paper will document the DLA's journey over the last year, explain how they use creativity to address end-of-life and document how they plan to support every UK hospice over the course of 2017.

\section{P-222 BREAKING TRADITION IN PALLIATIVE CARE- INTRODUCTION OF REMOTE TECHNOLOGY AND VIRTUAL CONSULTATIONS}

Sarah Roberts, Nicola Parkes, Susan Salt, Julie Huttley. Trinity Hospice, Blackpool, UK

\subsection{6/bmjspcare-2016-001245.243}

The aim of the project was to develop a strategic vision in three stages for the palliative care service to improve and expand our reach to patients that incorporated the use of technology. The project aimed to use virtual technology to open up access for consultant led advice in the patients home via video link consultation. This would allow more access to face to face consultations, a more responsive service, less travel time and more access to allow a "tech savvy" population to connect directly with the service.

The second aim of the project was to allow the service to utilise technology to enhance sharing of knowledge and skills to our community colleagues, opening up access to web based educational "bitesize" programmes to improve and enhance skills of our community colleagues.

The final aim of the project is to utilise technology to connect with our community partners to enhance communication and consultation with and about patients. We would use this with our out of hours providers as part of a community hub approach, using technology within the patients home to seek direct clinical advice enhanced by video links.

\section{P-223 PATIENT AND CARER PORTAL}

Nick Middleton, Matt Smith. St Margaret's Hospice, Taunton, UK

\subsection{6/bmjspcare-2016-001245.244}

The Patient and Carer Portal is a multi-layered secure website that is being developed to enable professionals and patients to access our electronic patient records.
Key stakeholders will also be able to access tele-health and educational information and content through the online platform.

Innovative Technology This portal is just one of the ways technology can be used to reach out to more people, and allow us to spread the already stretched funding a little bit further.

Once launched, the platform will continue to grow and help us reach patients in their own homes, where they can receive tele-health services and add notes directly into their own patient record.

Reaching more patients, now and in the future A number of additional features will be released in stages over the next few years, slowly growing the service to reach out to more people and services. This will include the ability to self-refer, and for professionals to refer online 24 hours a day, 7 days a week, 365 days a year.

Tailored to Individuals In addition to providing patients and professionals with remote access to medical records thus allowing them to read notes and directly update the records themselves 'prescribed' information, specifically tailored to the individual patient, will also be available through the Portal.

Educational Content Instructional videos for patients and professionals will also be accessible through the portal. Examples include: therapeutic audio/visual services and content, developed in-house by our highly experienced and professional therapies team (i.e., a self-help video on 'How to deal with breathlessness').

\section{Workforce, Volunteers, Leadership, Education and Workplace}

\section{P-224 CREATION OF A NEW STARTER INFORMATION PACK FOR REGISTERED NURSES IN A HOSPICE IN PATIENT UNIT}

Gemma Hodge, Sharon Allman. St Gemma's Hospice, Leeds, UK

\subsection{6/bmjspcare-2016-001245.245}

'There is still a workforce crisis in the NHS the number one priority for health care providers is making sure they have enough staff to deliver safe care' Davies (2016). This is certainly something we have experienced and as a result in the hospice where previously applications would be from nurses in palliative care we are now employing many nurses from a variety of backgrounds, so their palliative care knowledge can be limited.

Due to this shift in experience, we notice that inducting new starters was more complex than it had been. Entering Palliative care nursing can be very daunting for nurses coming from different specialities, particularly with the doses of medications used 'off licence' (Twycross et al., 2014) that we use to achieve symptom management. We therefore wanted new staff to feel empowered and valued, and felt that through providing them with an information pack when we are encouraging them to think about their knowledge gaps, giving them an information resource and guiding them through that period of induction.

Process of Implementation- What is current in education, relevant e-Learning, introduction to equipment we used, worksheets on key issues in palliative care to engage thinking around topics, face to face sessions on complex issues with advanced nurse practitioner, pharmacist and nurse consultant and requirement to complete a reflection. Feedback was very positive. Inclusion of 